\title{
Sorafenib with doxorubicin augments cytotoxicity to renal cell cancer through PERK inhibition
}

\author{
MASAKI SHIOTA $^{1}$, MASATOSHI ETO $^{3}$, AKIRA YOKOMIZO ${ }^{1}$, YASUHIRO TADA ${ }^{1}$, ARIO TAKEUCHI ${ }^{1}$, \\ DAISUKE MASUBUCHI ${ }^{1}$, JUNICHI INOKUCHI ${ }^{1}$, KATSUNORI TATSUGAMI $^{1}$, KENTARO KUROIWA $^{1}$, \\ TAKESHI UCHIUMI ${ }^{2}$, NARIHITO SEKI ${ }^{1}$ and SEIJI NAITO ${ }^{1}$
}

Departments of ${ }^{1}$ Urology and ${ }^{2}$ Clinical Chemistry and Laboratory Medicine, Graduate School of Medical Sciences, Kyushu University, Fukuoka; ${ }^{3}$ Department of Urology, Graduate School of Medicine,

Kumamoto University, Kumamoto, Japan

Received December 22, 2009; Accepted February 10, 2010

DOI: 10.3892/ijo_00000639

\begin{abstract}
Although cytokine therapy involving interleukin-2 or interferon- $\alpha$ has been employed for metastatic renal cell cancer (RCC) treatment, these therapies yielded limited response and benefit. Recently, several molecular-targeted agents have become available, and one newly developed anti-RCC agent, sorafenib (BAY 43-9006), is known to target multiple kinases. In this study, sorafenib was found to inhibit phosphorylation of the eukaryotic initiation factor- $2 \alpha(\mathrm{eIF} 2 \alpha)$ and induce cell cycle arrest at G2/M phase and increase cell death. One of eIF2 $\alpha$ kinases, PERK was responsible for eIF2 $\alpha$ phosphorylation in RCC cells and PERK knockdown induced cell death similar to sorafenib treatment. The efficiency of sorafenib treatment correlated with phosphorylation level of eIF2 $\alpha$ and nuclear Nrf2 expression level in eight RCC cell lines. Furthermore, sorafenib made Caki-1 and 786-O cells, but not ACHN cells sensitive to oxidative stress exerted by both hydrogen peroxide and doxorubicin. In addition, PERK knockdown sensitized Caki-1 and 786-O cells, but not ACHN cells to oxidative stress. In conclusion, levels of phospho-eIF2 $\alpha$ and nuclear Nrf2 expression level in RCC might be a predictor of outcome in sorafenib treatment. In addition, PERK inhibition as well as sorafenib plus doxorubicin might be a promising therapeutic approach for RCC characterized by high levels of phosphorylatedeIF2 $\alpha$ and nuclear Nrf2.
\end{abstract}

\section{Introduction}

Renal cell cancer (RCC) is characterized by the loss of von Hippel-Lindau tumor suppressor protein, resulting in dys-

Correspondence to: Dr Seiji Naito, Department of Urology, Graduate School of Medical Sciences, Kyushu University, 3-1-1 Maidashi, Higashi-ku, Fukuoka 812-8252, Japan

E-mail: naito@uro.med.kyushu-u.ac.jp

Key words: eIF2 $\alpha$, doxorubicin, renal cell cancer, PERK, sorafenib regulation of growth factor signaling, including vascular endothelial growth factor (VEGF), platelet-derived growth factor (PDGF) and transforming growth factor- $\alpha$ (TGF- $\alpha$ ). These factors play key roles in angiogenesis and lymphangiogenesis as well as in dysregulation of Raf pathways that regulate tumor growth and survival (1-6). Patients with metastatic RCC (mRCC) face a poor prognosis, with a historical median survival of 6-10 months and a 2-year survival of $10-20 \%$ (7). Traditional chemotherapy or radiotherapy has been relatively ineffective, with only $10 \%$ of the patients showing response to these treatments (8). Cytokine therapy involving interleukin-2 (IL-2) or interferon- $\alpha$ (IFN- $\alpha$ ) has also yielded limited benefit, with objective response rates of only $15 \%$ for both $(7,9,10)$. Combination therapies with IFN- $\alpha$ in RCC have involved using it together with IL-2, 5-fluorouracil, retinoic acid, and/or thalidomide; none of these studies has shown any consistent improvement in outcome over IFN- $\alpha$ monotherapy $(7,11-13)$. Thus, there are many requirements for new effective therapies for mRCC. Sorafenib (BAY 43-9006) is a novel bi-aryl urea that has been previously shown to inhibit Raf-1 and tumor cell line proliferation and tumor xenograft models $(14,15)$. In addition to Raf-1 inhibition, sorafenib is a multikinase inhibitor, which targets vascular endothelial growth factor receptor (VEGFR) 2 and 3; plateletderived growth factor receptor- $\beta$ (PDGFR- 3 ); FMS-like tyrosine kinase 3 (FLT3); c-Kit; and RET-receptor tyrosine kinase $(16,17)$. The clinical benefit of sorafenib was initially found in a phase II randomized trial, which indicated a lengthened progression-free survival with sorafenib compared with placebo in patients with mRCC refractory to cytokine therapy (18). A subsequent phase III randomized controlled trial [Treatment Approaches in Renal cancer Global Evaluation Trial (TARGET)] confirmed the findings of the phase II trial (19). We have previously conducted a phase II study to investigate the efficacy, safety, and pharmacokinetics of sorafenib in Japanese patients with advanced renal cell carcinoma, and revealed that sorafenib exerted encouraging efficacy and was well tolerated in Japanese patients with mRCC (20).

Phosphorylation of the eukaryotic initiation factor- $2 \alpha$ (eIF $2 \alpha$ ) is an important mechanism regulating protein synthesis in response to a diverse range of environmental stresses 
(21-23). Four eIF2 $\alpha$ kinases have been identified in mammals, each responding to different stresses through their unique regulatory regions. For example, phosphorylation of eIF $2 \alpha$ by PKR-like endoplasmic reticulum kinase (PERK, also known as EIF2AK3) is induced by accumulation of misfolded proteins in the endoplasmic reticulum (ER), a phenomenon designated as unfolded protein reaction (UPR) or ER stress (24-26). Phosphorylation of eIF $2 \alpha$ during ER stress inhibits global translation by lessening eIF2-GTP (21-23). Together with reduced protein synthesis, eIF2 $\alpha$ phosphorylation increases the preferential translation of ATF4 mRNA, encoding a basic zipper transcription activator that is important for directing the expression of genes involved in metabolism, the redox status of cells and apoptosis (27-29). Furthermore, eIF2 $\alpha$ phosphorylation has been shown to regulate an expression of NF-E2-related factor 2 (Nrf2), which is the Cap ' $n$ ' Collar transcription factor closely involved in oxidative stress response through expression of phase II antioxidative stress proteins (30). Decreased protein synthesis conserves energy and provides sufficient time for ATF4, Nrf2 and other stressresponsive transcription factors, to reconfigure gene expression that would block or ameliorate damage elicited by the underlying stress. Other members of the eIF2 $\alpha$ kinase family include GCN2 (EIF2AK4), whose activity is enhanced by amino acid depletion, UV irradiation or proteasome inhibition; PKR (EIF2AK2), which function in an antiviral pathway; and HRI (EIF2AK1), which is regulated by heme deficiency and oxidative stress $(22,23,26,31)$. Aberrations in these eIF $2 \alpha$ kinase pathways are associated with a number of diseases, including diabetes, viral infection, anemia, neurological disorders and various cancers.

In this study, we investigated whether the multikinase inhibitor, sorafenib could inhibit the eIF $2 \alpha$ kinase family. Then, we attempted to elucidate a mechanism that sorafenib inhibited RCC-cell growth through an inhibition of eIF $2 \alpha$ kinase pathway and provide a possible molecular marker of RCC-cell sensitivity to sorafenib. Furthermore, to improve treatment of mRCC patients, we investigated the effects of combined therapy of conventional chemotherapy and sorafenib based on a pharmacological effect of sorafenib toward eIF $2 \alpha$ kinase pathway.

\section{Materials and methods}

Cell culture and chemical. Human renal cell cancer KG2, KPK13, SKR1, KPK1 and SN12C cells were established and maintained as described previously (32-35). KG2 cells were a kind gift of Dr Kazuo Gohji (Kobe University, Kobe, Japan). Human renal cell cancer Caki-1 cells were cultured in Eagle's minimal essential medium (Invitrogen, San Diego, CA, USA). Human renal cell cancer ACHN and 786-O cells were cultured in Eagle's minimal essential medium (Sigma, St. Louis, MO, USA) and RPMI1640 (Sigma), respectively. These media were contained $10 \%$ fetal bovine serum. Cell lines were maintained in a $5 \% \mathrm{CO}_{2}$ atmosphere at $37^{\circ} \mathrm{C}$. Sorafenib was obtained from Bayer Pharmaceuticals Corp. (West Haven, CT, USA). For assay, stock solution was prepared in dimethyl sulfoxide (DMSO) $(10 \mathrm{mM})$, and stored at $-20^{\circ} \mathrm{C}$ until use. Stock solution was diluted to appropriate concentration in culture medium before addition to the cells.
Antibodies. Antibodies against GCN2 (\#3302), p-PERK (\#3191), p-eIF2 $\alpha$ (\#9721), eIF2 $\alpha$ (\#2103) and p-ERK1/2 (\#9106) were purchased from Cell Signaling Technology (Danvers, MA, USA). Antibody against ERK1 (sc-94) and PERK (sc-13073) were purchased from Santa Cruz Biotechnology (Santa Cruz, CA, USA). Anti-Nrf2 (\#2178-1), anti-p-GCN2 (\#2313-1), anti-PKR (\#1511-1) and anti-p-PKR (\#2283-1) antibodies were purchased from Epitomics (Burlingame, CA, USA). Anti-Lamin B1 and anti-ß-actin antibodies were purchased from Sigma.

Western blotting. Whole-cell and nuclear extracts were prepared with phosphatase inhibitor Cocktail (Nacalai tesque, Kyoto, Japan) as previously described (36-40). The protein concentration was determined using a Protein Assay Kit (Bio-Rad, Hercules, CA), based on the Bradford method. Whole-cell and nuclear extracts $(30 \mu \mathrm{g})$ were separated by SDS-PAGE and transferred to polyvinylidene difluoride microporous membranes (GE Healthcare Bio-Science, Piscataway, NJ, USA) using a semi-dry blotter. The blotted membranes were incubated for $1 \mathrm{~h}$ at room temperature with a primary antibody. Membranes were then incubated for $40 \mathrm{~min}$ at room temperature with a peroxidase-conjugated secondary antibody. The bound antibody was visualized using an ECL kit (GE Healthcare Bio-Science) and membranes were exposed to Kodak X-OMAT film. For the correlation assay, the intensity of each signal was quantified using the NIH Imaging program, version 1.62 (NIH, Bethesda, MD, USA).

Flow cytometry analysis. Flow cytometry analysis was performed as described previously (36). Briefly, Caki-1, 786-O and ACHN cells $\left(2.0 \times 10^{5}\right)$ were seeded in 6-well plates, applied to $10 \mu \mathrm{M}$ of sorafenib and cultured for $24 \mathrm{~h}$, or transfected with $40 \mathrm{nM}$ of the indicated siRNA and cultured for $72 \mathrm{~h}$. The cells were harvested, washed twice with ice-cold PBS containing $0.1 \%$ bovine serum albumin (BSA) and resuspended in 70\% ethanol. After washing twice with ice-cold PBS, cells were resuspended in PBS containing $0.1 \%$ BSA, incubated with RNase (Roche Applied Science, Indianapolis, IN, USA) and stained with propidium iodide (Sigma). Cells were analyzed using a FACSCalibur (BD Biosciences, San Jose, CA, USA).

Knockdown analysis using siRNAs. Knockdown analysis using siRNAs was performed as described previously (36-40). Briefly, the following double-stranded RNA oligonucleotides were commercially generated: 5'-GGUAAAAAGCAGUGG GAUUTT-3' (sense) and 5'-AAUCCCACUGCUUUUUAC CTT-3' (antisense) for PERK \#1 (B-Bridge International, Mountain View, CA, USA); 5'-GGGAAAAGGUAAUGCG AGATT-3' (sense) and 5'-UCUCGCAUUACCUUUUCC CTT-3' (antisense) for PERK \#2 (B-Bridge International); 5'-CCACAUGAUAGGAGGUUUATT-3' (sense) and 5'UAAACCUCCUAUCAUGUGGTT-3' (antisense) for PKR (B-Bridge International); 5'-AUUAGAUGCACUCAGGAC CUUAUGC-3' (sense) and 5'-GCAUAAGGUCCUGAGUG CAUCUAAU-3' (antisense) for GCN2 (Invitrogen). Caki-1, 786-O and ACHN cells were transfected with $40 \mathrm{nM}$ of the indicated siRNA using Lipofectamine 2000 (Invitrogen) according to the manufacturer's instructions. 
$\mathbf{A}$

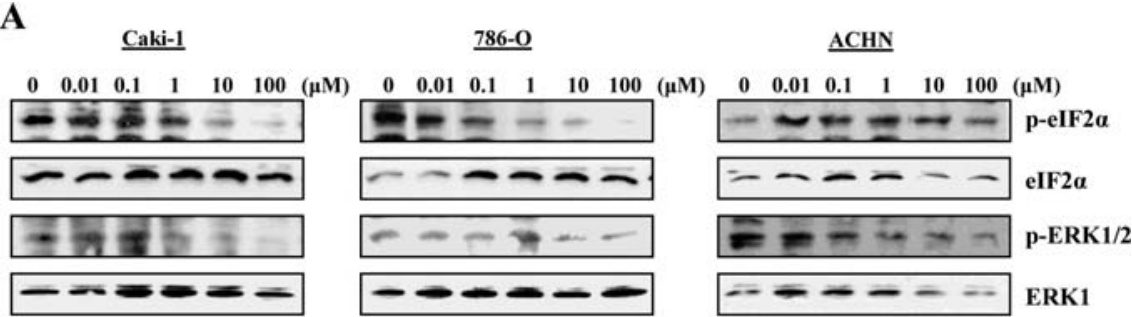

B

Caki-1

$\underline{786-0}$

$\underline{\mathrm{ACHN}}$

$\begin{array}{llllllllllllllll}0 & 0.5 & 2 & 6 & \text { (h) } & 0 & 0.5 & 2 & 6 & \text { (h) } & 0 & 0.5 & 2 & 6 & \text { (h) }\end{array}$

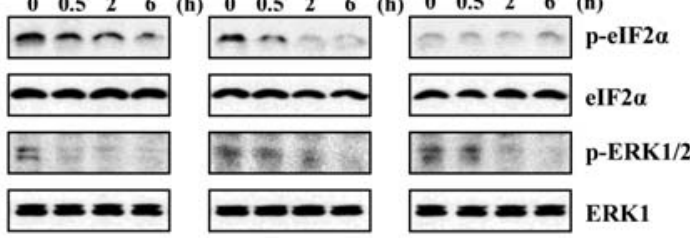

D
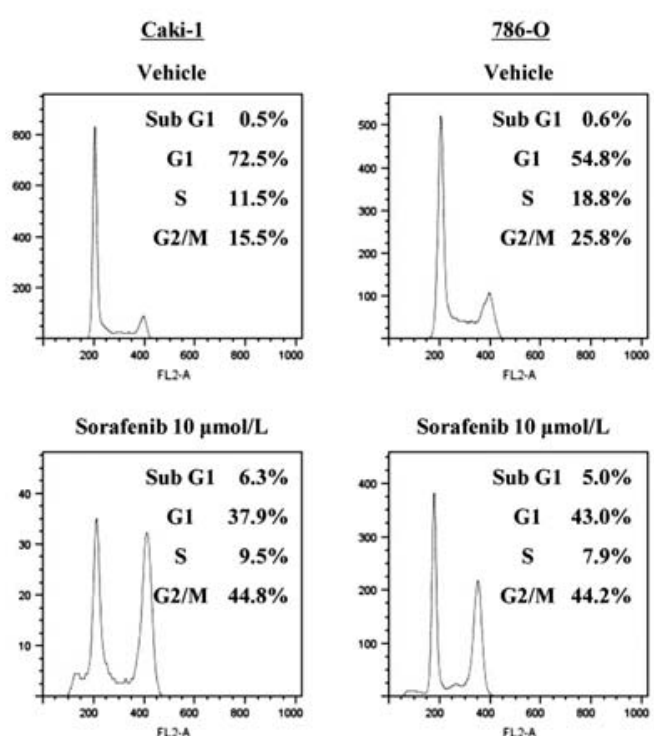

C
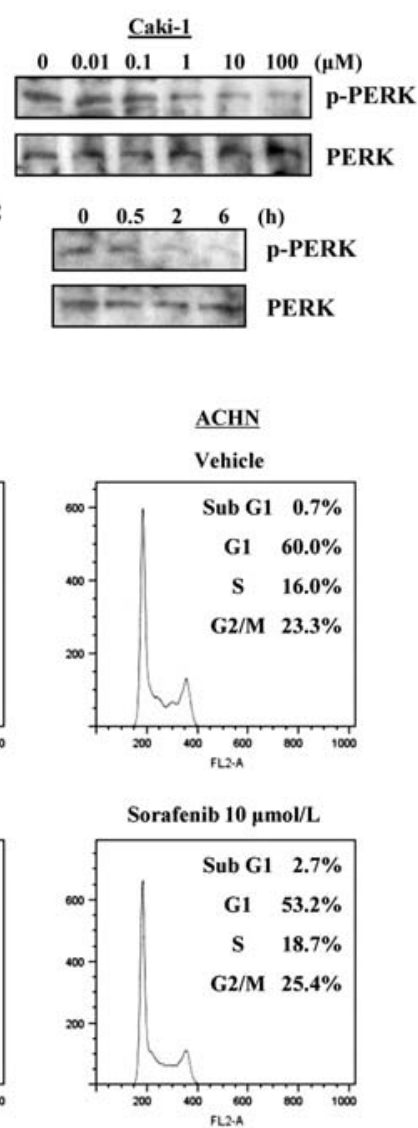

Figure 1. Sorafenib reduces phosphorylated form of eIF2 $\alpha$ and ERK1/2, and induces cell-cycle arrest at G2 phase and cellular apoptosis in Caki-1 and 786-O cells. (A) Caki-1, 786-O and ACHN cells were cultured with various concentrations of sorafenib for $6 \mathrm{~h}$, and the cells were harvested. Whole-cell extracts were subjected to SDS-PAGE, and Western blotting was performed using the indicated antibodies. (B) Caki-1, 786-O and ACHN cells were cultured with $10 \mu \mathrm{M}$ of sorafenib for various durations, and the cells were harvested. Whole-cell extracts were subjected to SDS-PAGE, and Western blotting was performed using the indicated antibodies. (C) Caki-1 cells were cultured with various concentrations of sorafenib for $6 \mathrm{~h}$ or $10 \mu \mathrm{M}$ of sorafenib for various durations, and the cells were harvested followed by $0.5 \mu \mathrm{g} / \mathrm{ml}$ of tunicamycin treatment for $6 \mathrm{~h}$. Whole-cell extracts were subjected to SDS-PAGE, and Western blotting was performed using the indicated antibodies. (D) Caki-1, 786-O and ACHN cells were applied to vehicle or $10 \mu \mathrm{M}$ of sorafenib for $24 \mathrm{~h}$, and the cells were stained with propidium iodide and analyzed by flow cytometry. The cell cycle fractions are shown at the top right of each graph.

Cytotoxicity analysis. Cytotoxicity analysis was performed as described previously $(36,38,40)$. Briefly, Caki-1, 786-O and ACHN cells $\left(2.5 \times 10^{3}\right)$ applied to $0.5 \mu \mathrm{M}$ of sorafenib or transfected with $40 \mathrm{nM}$ of the indicated siRNA were seeded into 96-well plates. The following day, the indicated concentrations of hydrogen peroxide or doxorubicin and/or $\mathrm{N}$-acetyl-L-cysteine (NAC) were applied. After $48 \mathrm{~h}$, surviving cells were stained with alamarBlue Assay (TREK Diagnostic systems, Cleaveland, $\mathrm{OH}, \mathrm{USA}$ ) for $180 \mathrm{~min}$ at $37^{\circ} \mathrm{C}$. The absorbance was then measured using a plate reader $\left(\mathrm{ARVO}^{\mathrm{TM}}\right.$ MX, Perkin-Elmer Inc., Waltham, MA, USA).

Determination of inhibitory concentration $50\left(I C_{50}\right)$ to sorafenib in RCC cells. Eight RCC cell types $\left(2.5 \times 10^{3}\right)$ were seeded into 96-well plates. The following day, the various concentrations of sorafenib were applied. After $48 \mathrm{~h}$, cytotoxicity assay was performed as described above. Then, $\mathrm{IC}_{50}$ was defined as sorafenib concentration when $50 \%$ of cells survived.

\section{Results}

Sorafenib reduces eIF $2 \alpha$ phosphorylation levels and induces cell cycle arrest at G2/M phase and cell death. To investigate whether multikinase inhibitor, sorafenib could inhibit the eIF $2 \alpha$ kinase family, Western blot analysis was performed after RCC cells were treated with increasing concentrations of sorafenib. As shown in Fig. 1A, various concentrations of 
A

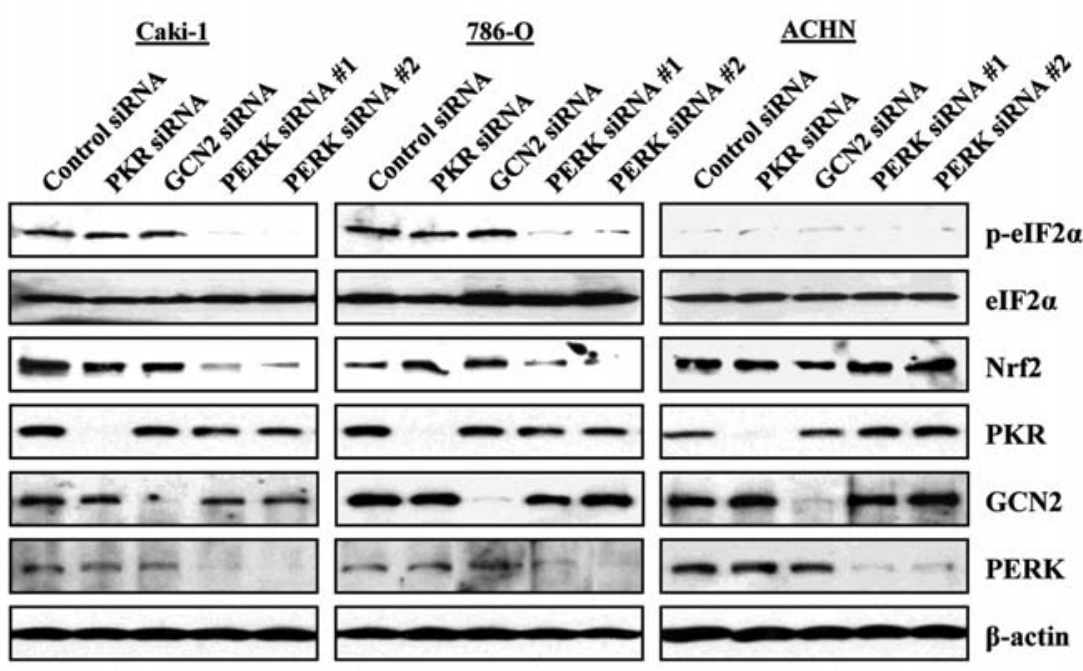

B

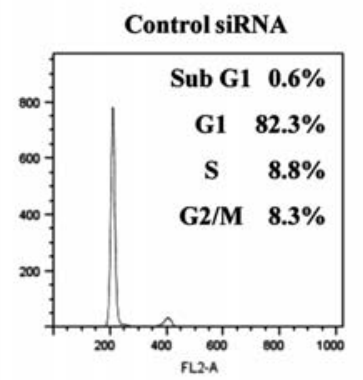

$\underline{\text { Caki-1 }}$
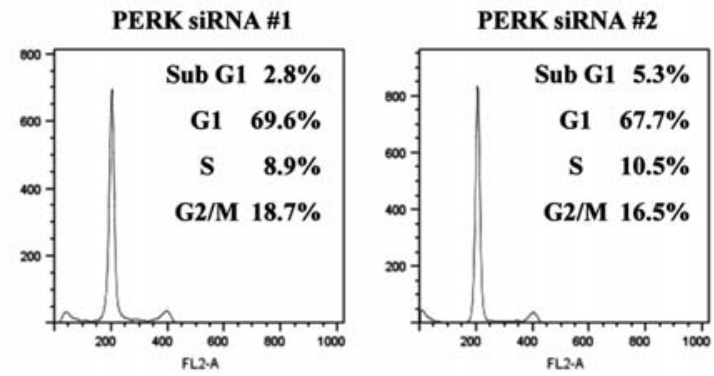

C

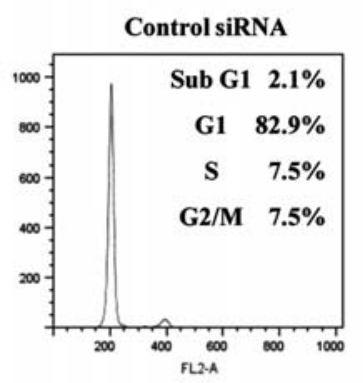

$\underline{786-0}$
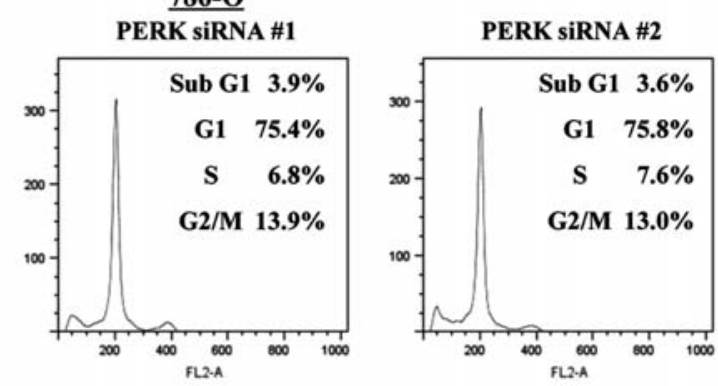

D
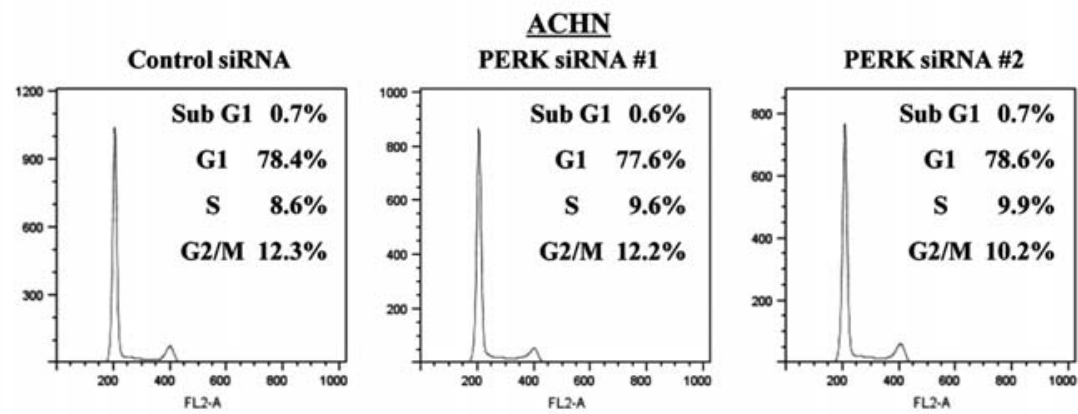

Figure 2. Silencing of PERK reduces phosphorylation form of eIF2 $\alpha$, and induces cell cycle arrest at G2 phase and cell death in Caki-1 and 786-O cells. (A) Caki-1, 786-O and ACHN cells were transfected with $40 \mathrm{nM}$ of control siRNA, PKR siRNA, GCN2 siRNA, PERK siRNA \#1 or PERK siRNA \#2. At $72 \mathrm{~h}$ after transfection, whole-cell extracts were subjected to SDS-PAGE, and Western blotting was performed using the indicated antibodies. (B-D) Caki-1 (B), 786-O (C) and ACHN (D) cells were transfected with $40 \mathrm{nM}$ of control siRNA, PERK siRNA \#1 or PERK siRNA \#2. At $72 \mathrm{~h}$ after transfection, cells were stained with propidium iodide and analyzed by flow cytometry. The cell cycle fractions are shown at the top right of each graph.

sorafenib treatment for $6 \mathrm{~h}$ reduced phosphorylation of ERK1/2 (p-ERK1/2) as well as phosphorylation of eIF2 $\alpha$ (p-eIF2 $\alpha)$ in Caki-1 and 786-O cells. On the contrary, p-eIF2 $\alpha$ level was increased in ACHN cells although p-ERK1/2 level declined. About $1 \mu \mathrm{M}$ of sorafenib inhibited phosphorylation of eIF2 $\alpha$ to $50 \%$ of vehicle treatment in Caki-1 and 786-O cells. When 
RCC cells were treated with $10 \mu \mathrm{M}$ of sorafenib for various durations, p-ERK1/2 as well as p-eIF2 $\alpha$ level declined in Caki- 1 and 786-O cells whereas p-eIF $2 \alpha$ did not in ACHN cells (Fig. 1B). There are four members of eIF2 $\alpha$ kinase family: PKR, GCN2, PERK, and HRI, the former three are expressed in RCC cells; HRI expression is restricted to erythroblast cells. To determine which p-eIF $2 \alpha$ kinase was responsible for dephosphorylation of eIF $2 \alpha$ by sorafenib treatment in Caki- 1 cells, immunoblotting for phosphorylated forms of these eIF2 $\alpha$ kinases was performed. The results showed sorafenib treatment decreased p-PERK level in concentration- and duration-dependent manner (Fig. 1C). On the other hand, pPKR and p-GCN2 levels were constant during sorafenib treatment (data not shown). Because sorafenib is known to suppress cell proliferation in RCC cells, we performed cell cycle analysis using flow cytometry analysis to investigate a mechanism of tumor growth suppression by sorafenib. First, Caki-1 cells were subjected to cell cycle analysis. Application of $10 \mu \mathrm{M}$ sorafenib induced cell cycle arrest at G2 phase and cellular death represented by sub-G1 fraction. Similar results were obtained when $786-\mathrm{O}$ cells were investigated. Of note, both Caki-1 and 786-O cells have high levels of p-eIF $2 \alpha$. On the other hand, ACHN cells possessing low eIF $2 \alpha$ phosphorylation status exhibited only a slight increase in the G2-phase fraction and little effect of cellular apoptosis as compared with either Caki-1 or 786-O cells (Fig. 1D).

PERK knockdown reduces eIF2a phosphorylation level and nuclear Nrf2 expression, and induces cell cycle arrest at G2 phase and cellular death. To confirm that PERK is the responsible eIF $2 \alpha$ kinase for eIF $2 \alpha$ phosphorylation in RCC cells, PKR, GCN2 and PERK eIF2 $\alpha$ kinases were silenced by the corresponding specific-siRNAs, then eIF2 $\alpha$ phosphorylation status was investigated by Western blot analysis. As shown in Fig. 2A, PERK knockdown using two kinds of PERKspecific siRNA decreased eIF2 $\alpha$ phosphorylation level in Caki-1 and 786-O cells, whereas PKR or GCN2 knockdown had no effect. This result also indicated that in Caki-1 and 786-O cells, PERK is mainly responsible for eIF2 $\alpha$ phosphorylation. In addition, Nrf2, whose expression is known to be regulated by PERK (30), decreased when only PERK was silenced. On the other hand, eIF2 $\alpha$ phosphorylation was hardly detected in ACHN cells, and Nrf2 expression level was slightly affected. We performed cell cycle analysis using flow cytometry to investigate a functional correlation between sorafenib and PERK inhibition. First, Caki-1 cells were subjected to cell cycle analysis and PERK knockdown induced cell cycle arrest at G2/M phase and cell death although at a lesser degree than sorafenib treatment (Fig. 2B). Similar results were obtained when 786-O cells which possess high eIF $2 \alpha$ phos-phorylation level similar to Caki-1 cells were investigated (Fig. 2C). On the other hand, ACHN cells possessing low eIF $2 \alpha$ phosphorylation level exhibited little effect on cell cycle and cell death (Fig. 2D).

Phosphorylation level of eIF $2 \alpha$ and nuclear Nrf2 expression level are correlated with efficiency of sorafenib treatment. Because the finding that sorafenib inhibits eIF2 $\alpha$ phosphorylation was revealed, whether eIF $2 \alpha$ phosphorylation level
Table I. IC $_{50}$ to sorafenib, phosphorylated eIF $2 \alpha /$ total eIF $2 \alpha$ and nuclear Nrf2 expression in RCC cell lines.

\begin{tabular}{lccc}
\hline $\begin{array}{l}\text { RCC } \\
\text { cell line }\end{array}$ & $\begin{array}{c}\mathrm{IC}_{50} \text { to } \\
\text { sorafenib } \\
(\mu \mathrm{M})\end{array}$ & $\begin{array}{c}\text { Phosphorylated } \\
\text { eIF2 } \alpha / \text { total } \\
\text { eIF2 } \alpha\end{array}$ & $\begin{array}{c}\text { Nuclear } \\
\text { Nrf2 } \\
\text { expression }\end{array}$ \\
\hline Caki-1 & 7.8 & 0.99 & 0.31 \\
KG2 & 8.8 & 0.79 & 0.36 \\
KPK13 & 18 & 0.12 & 0.13 \\
SKR1 & 11 & 0.17 & 0.54 \\
KPK1 & 12 & 0.05 & 0.28 \\
786-O & 6.5 & 1 & 1 \\
ACHN & 10 & 0.12 & 0.51 \\
SN12 & 14 & 0.08 & 0.13 \\
\hline
\end{tabular}

and nuclear Nrf2 expression level could predict an efficiency of sorafenib treatment in RCC cells was examined. First, eight RCC cell lines were subjected to Western blot analysis. Because sorafenib is well-known to inhibit ERK phosphorylation, p-ERK1/2 and ERK1 in addition to p-eIF2 $\alpha, \operatorname{eIF} 2 \alpha$ and Nrf2 were investigated in untreated cells. Although ERK1/2 phosphorylation status was high in ACHN cells, basal eIF $2 \alpha$ phosphorylation status and nuclear Nrf2 expression level were high in 786-O cells (Fig. 3A). As speculated from previous finding (30), correlation between eIF $2 \alpha$ phosphorylation status and nuclear Nrf2 expression level was suggested. In RCC cells, coefficient of correlation between basal eIF $2 \alpha$ phosphorylation status and nuclear Nrf2 expression level was 0.50 although not significant statistically (Fig. 3B). Next, $\mathrm{IC}_{50}$ for cell-growth inhibitory effects of sorafenib was determined in these eight RCC cell lines. As shown in Table I, 786-O cells were most sensitive to sorafenib whereas KPK13 cells were most resistant and ACHN cells were relatively resistant. To reveal a possible predictor of sensitivity to sorafenib treatment, correlations between either eIF $2 \alpha$ phosphorylation status or nuclear Nrf2 expression level and sorafenib $\mathrm{IC}_{50} \mathrm{~s}$ were examined. The results showed that both basal eIF2 $\alpha$ phosphorylation status and nuclear Nrf2 expression level were inversely correlated with $\mathrm{IC}_{50}$ value of RCC cells to sorafenib. Coefficients of correlation between eIF2 $\alpha$ phosphorylation status and $\mathrm{IC}_{50}$ value, and nuclear $\mathrm{Nrf} 2$ expression level and $\mathrm{IC}_{50}$ value were $-0.75(\mathrm{p}=0.033)$ and $-0.73(\mathrm{p}=0.040)$, respectively (Fig. 3C and D).

Sorafenib sensitizes both Caki-1 and 786-O cells to oxidative stress exerted by hydrogen peroxide and doxorubicin. Although mRCC was believed to be resistant to conventional chemotherapy (8), conventional chemotherapy combined with sorafenib may be useful to improve treatment outcome. Sorafenib was shown to suppress nuclear Nrf2 expression, which regulates several antioxidative stress proteins. First, cytotoxicity of hydrogen peroxide to RCC cells treated with sorafenib was investigated. Hydrogen peroxide combined with sorafenib suppressed Caki-1 and 786-O cell viability more effectively compared with hydrogen peroxide alone, although 
A

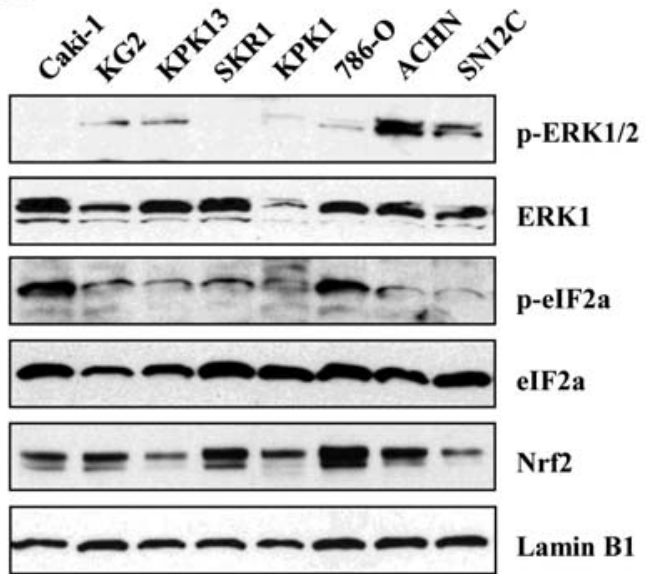

B

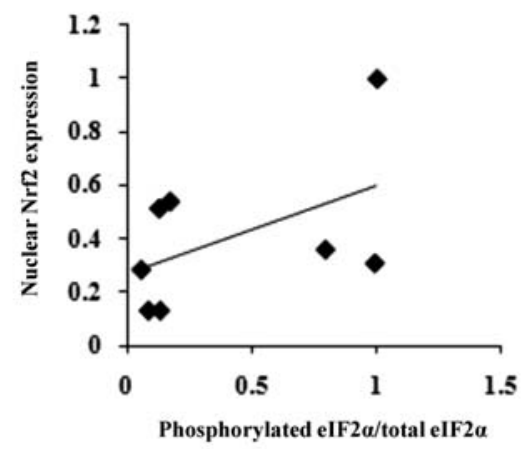

Coefficient of correlation $=\mathbf{0 . 5 0}$

$P$ value $=0.21$

D

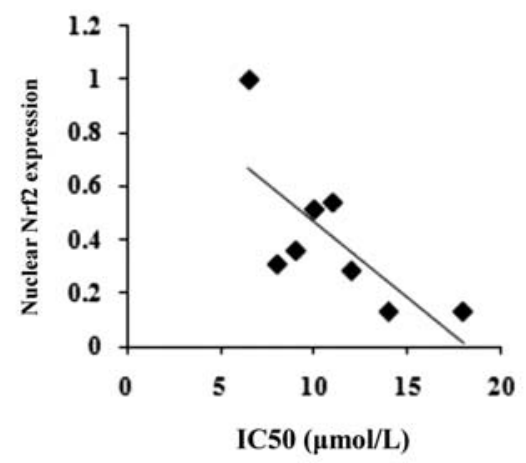

Coefficient of correlation $=-\mathbf{0 . 7 3}$

$P$ value $=0.040$

Figure 3. Phosphorylation level of eIF2 $\alpha$ and nuclear Nrf2 expression level are correlated with efficiency of sorafenib treatment. (A) Western blot analysis was performed with whole-cell extracts (p-ERK1/2, ERK1, p-eIF2 $\alpha$ and eIF2 $\alpha$ ) and nuclear extract (Nrf2 and Lamin B1) from eight RCC cell lines using the indicated antibodies. (B) Correlation between phosphorylation ratio to total eIF $2 \alpha$ and nuclear Nrf 2 expression level were analyzed. The maximum levels of phosphorylation ratio to total eIF2 $\alpha$ and nuclear Nrf2 expression in 786-O cells were set to 1 . (C) Correlation between $\mathrm{IC}_{50}$ to cytotoxicity of sorafenib and phosphorylated eIF $2 \alpha$ ratio to total eIF $2 \alpha$ in untreated cells was analyzed. (D) Correlation between $\mathrm{IC}_{50}$ to cytotoxicity of sorafenib and nuclear Nrf 2 expression level was analyzed.

ACHN cells were not affected by an addition of sorafenib (Fig. 4A). To investigate a mechanism of an additional effect of sorafenib to hydrogen peroxide, we assayed cytotoxicity of hydrogen peroxide combined with sorafenib and with NAC antioxidant added. When NAC was added, the enhancement of hydrogen peroxide on sorafenib activity was abolished in Caki-1 and 786-O cells (Fig. 4B).

Doxorubicin is well known to exert oxidative stress to cells (41). The cytotoxicity of RCC cells to doxorubicin combined with sorafenib was investigated. As shown in Fig. 4C, sorafenib could increase the sensitivity of Caki-1 and 786-O cells, but not of ACHN cells, to doxorubicin. In addition, NAC abolished this favorable effect of sorafenib similar to hydrogen peroxide combined with sorafenib (Fig. 4D).

PERK knockdown sensitizes both Caki-1 and 786-O cells to oxidative stress exerted by hydrogen peroxide and doxorubicin. Because sorafenib was suggested to inhibit PERK-kinase activity, the effects of PERK knockdown using PERK-specific siRNAs on RCC viability was determined. First, cytotoxicity of hydrogen peroxide to RCC cells transfected with PERKspecific siRNAs was examined. Hydrogen peroxide with PERK knockdown suppressed survival of Caki-1 and 786-O cells more effectively compared with hydrogen peroxide alone, although survival of ACHN cells were not affected by silencing of PERK (Fig. 5A). To confirm a mechanism of an additional effect of PERK knockdown to hydrogen peroxide, we assayed cytotoxicity of hydrogen peroxide with PERK knockdown when further NAC was added. When NAC was added to hydrogen peroxide combined with PERK knockdown, the enhanced cytotoxicity was abolished in Caki-1 and 786-O cells (Fig. 5B).

Similarly, doxorubicin plus PERK knockdown increased cytotoxicity to both Caki-1 and 786-O cells, but not to ACHN cells (Fig. 5C). In addition, NAC abolished the enhancement of doxorubicin plus PERK knockdown similar to hydrogen peroxide with PERK knockdown (Fig. 5D).

Doxorubicin sensitizes both Caki-1 and 786-O cells to sorafenib. Because sorafenib sensitized doxorubicin in RCC cells possessing high levels of eIF $2 \alpha$ phosphorylation status 
A

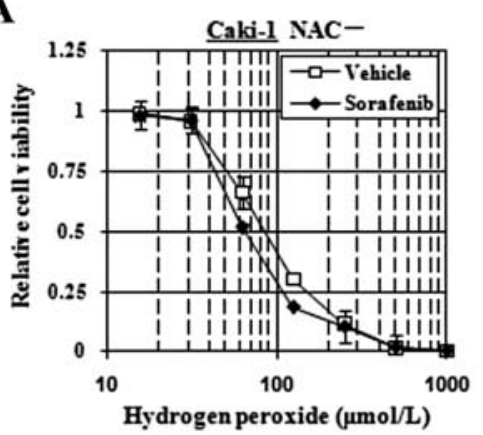

B

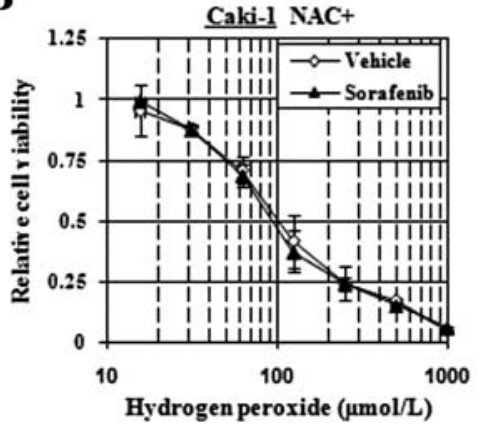

C

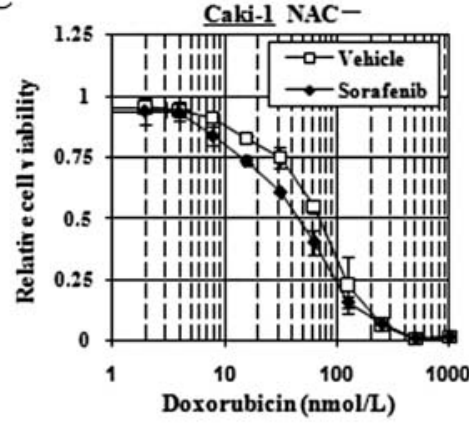

D

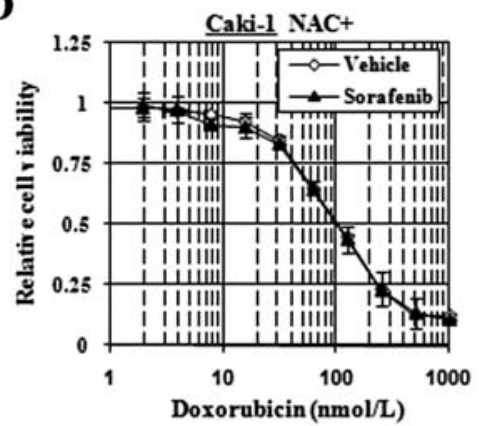

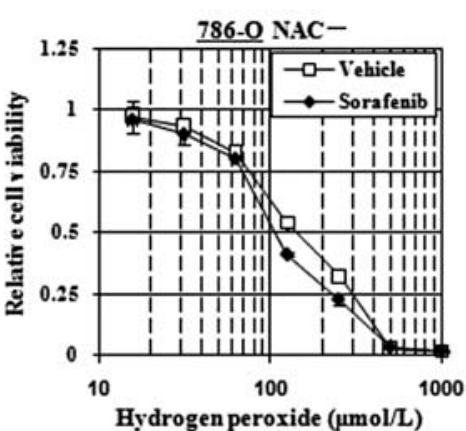
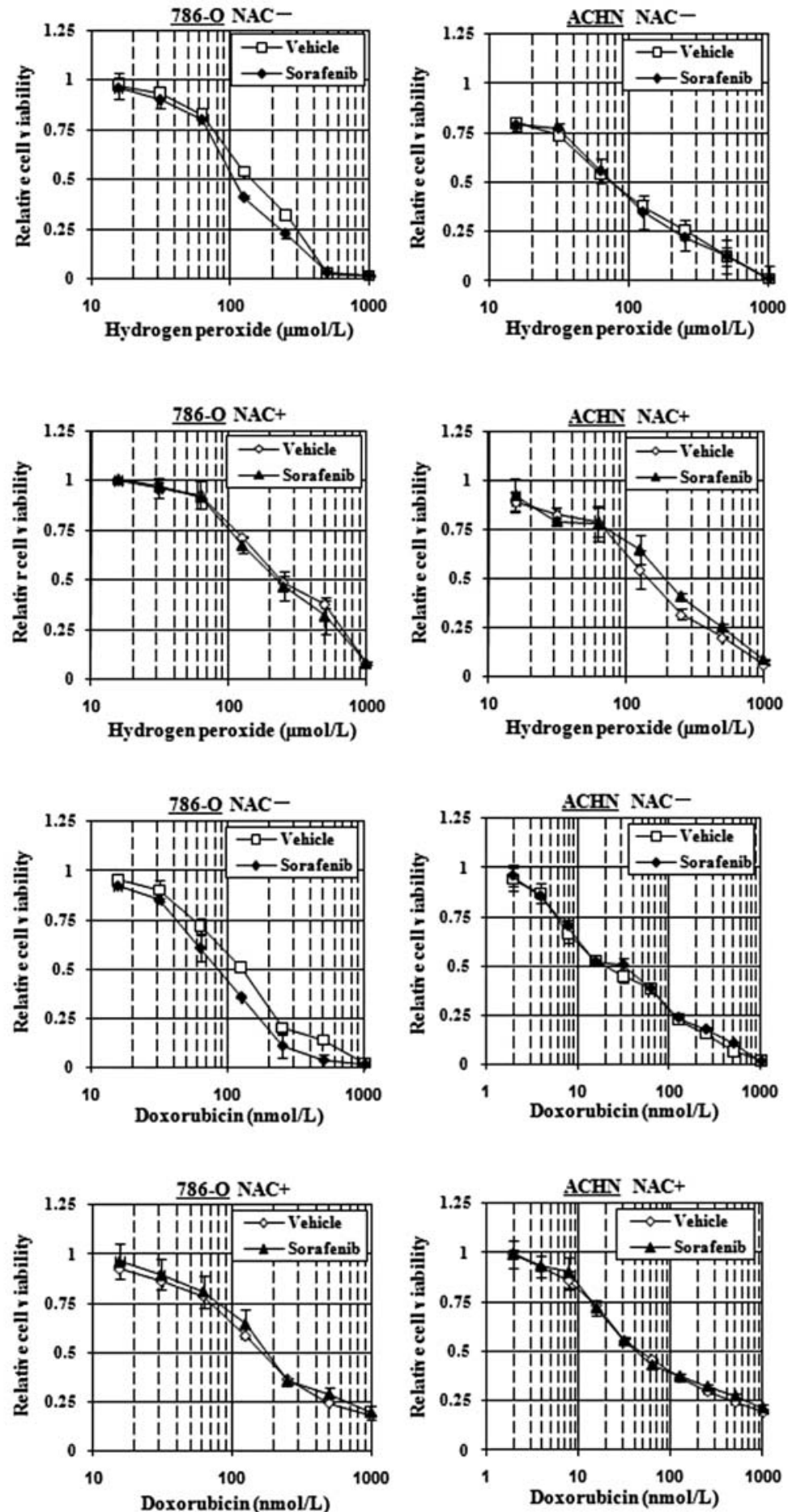

Figure 4. Sorafenib sensitizes both Caki-1 and 786-O cells to oxidative stress exerted by hydrogen peroxide and doxorubicin. (A and C) Caki-1, 786-O and ACHN cells were seeded into 96-well plates and treated with $0.5 \mu \mathrm{M}$ of sorafenib. The following day, various concentrations of hydrogen peroxide (A) or doxorubicin (C) were applied. After $48 \mathrm{~h}$, cell survival was analyzed by cytotoxicity assay. Cell survival in the absence of hydrogen peroxide (A) or doxorubicin (C) was set as 1. All values are representative of at least three independent experiments. Boxes, mean; bars \pm SD (B and D) Caki-1, 786-O and ACHN cells treated with $0.5 \mu \mathrm{M}$ of sorafenib and $5 \mathrm{mM}$ of NAC were seeded into 96-well plates. The following day, various concentrations of hydrogen peroxide (B) or doxorubicin (D) were applied. Cytotoxicity assay was performed as described in (A) and (C). Boxes, mean; bars \pm SD.

and nuclear Nrf2 expression, whether doxorubicin could sensitize RCC cells to sorafenib was investigated. As shown in Fig. 6A and B, doxorubicin sensitized both Caki-1 and 786-O cells to sorafenib about 2-fold. As expected, ACHN cells could not be sensitized to sorafenib by an addition of doxorubicin (Fig. 6C).

\section{Discussion}

Sorafenib has been shown to exert an anti-tumor effect through inhibition of multiple kinases, such as Raf-1, VEGFR 2 and 3, PDGFR- $\beta$, FLT3, c-Kit and RET-receptor tyrosine kinase $(16,17)$. A possible involvement of ER stress and generation 
A

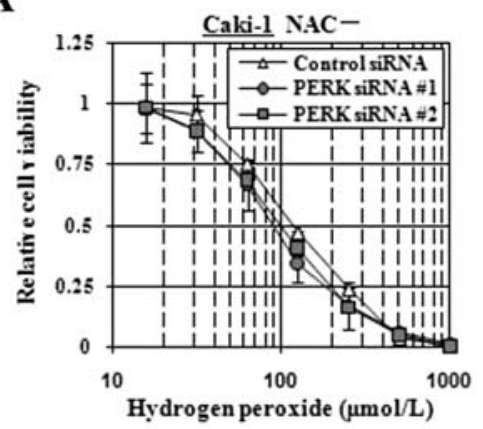

B

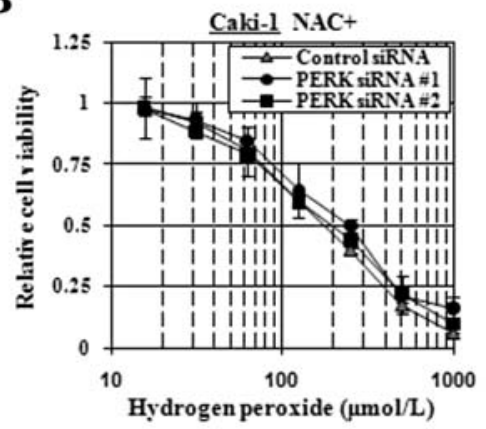

C

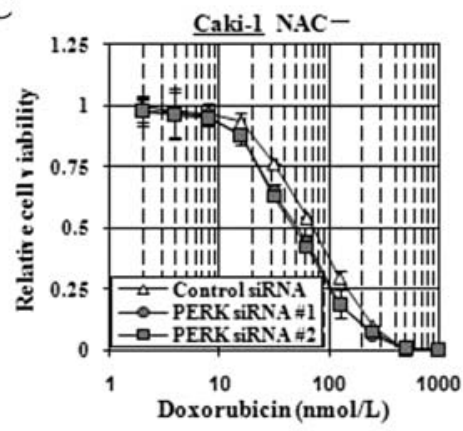

D

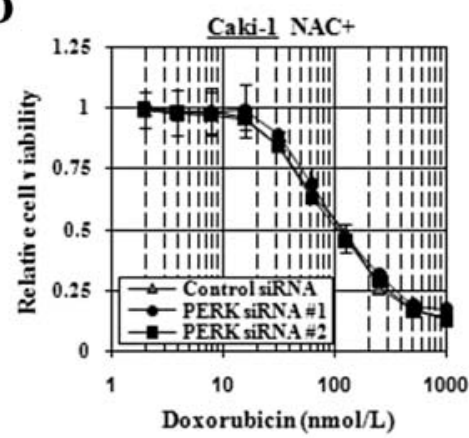

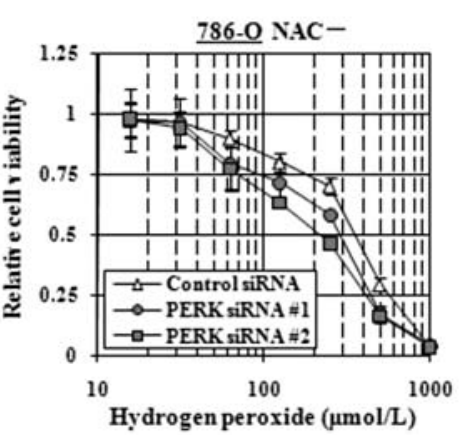
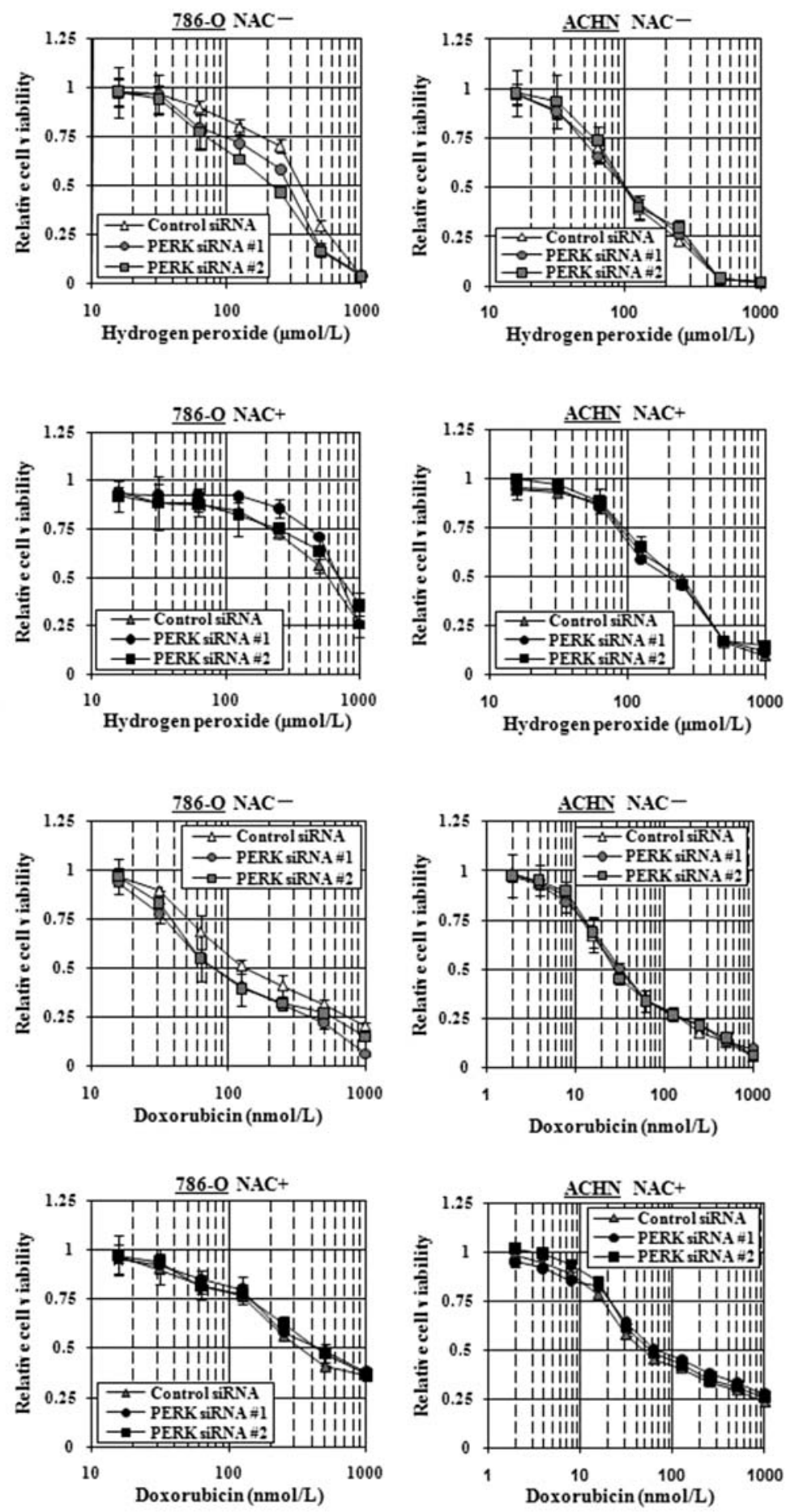

Figure 5. PERK knockdown sensitizes both Caki-1 and 786-O cells to oxidative stress exerted by hydrogen peroxide and doxorubicin. (A and C) Caki-1, 786-O and ACHN cells transfected with $40 \mathrm{nM}$ of control siRNA, PERK siRNA \#1 or PERK siRNA \#2 were seeded into 96-well plates. The following day, various concentrations of hydrogen peroxide (A) or doxorubicin $(\mathrm{C})$ were applied. After $48 \mathrm{~h}$, cell survival was analyzed by cytotoxicity assay. Cell survival in the absence of hydrogen peroxide (A) or doxorubicin (C) corresponds to 1. All values are representative of at least three independent experiments. Boxes, mean; bars \pm SD (B and D) Caki-1, 786-O and ACHN cells transfected with $40 \mathrm{nM}$ of control siRNA, PERK siRNA \#1 or PERK siRNA \#2, and treated with $5 \mathrm{mM}$ of NAC were seeded into 96-well plates. The following day, various concentrations of hydrogen peroxide (B) or doxorubicin (D) were applied. Cytotoxicity assay was performed as described in (A and C). Boxes, mean; bars \pm SD.

of reactive oxygen species in the cytotoxicity of sorafenib against leukemia cells has been reported (42). The role of ER stress in pancreatic function has been well characterized. Pancreatic $\beta$-islet cells produce large amounts of pro-insulin proteins and are continuously exposed to ER stress and must control the protein-synthesis process to protect themselves from over-dosing ER stress. Therefore, pancreatic $\beta$-islet cells regulate protein synthesis at the translational level. In this process of translation control, PERK plays a critical role to phosphorylate eIF2 $\alpha$ and repress translation; with the exception of ATF4. Mutations in PERK were shown to induce diabetes mellitus through apoptosis of pancreatic $\beta$-islet cells, 
A

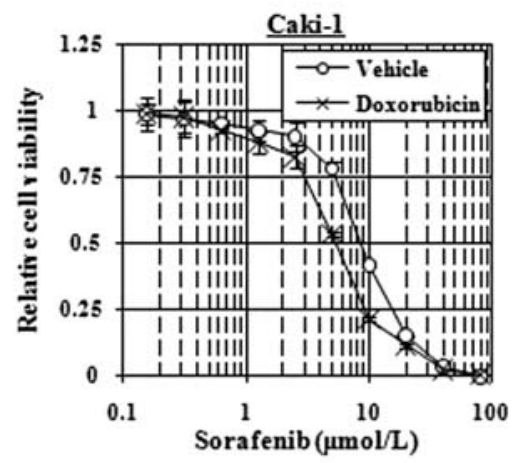

B

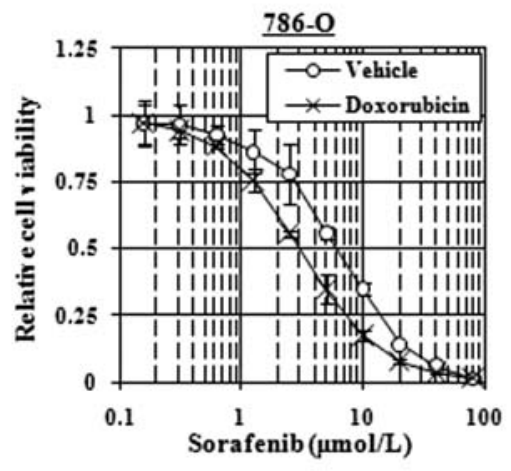

C

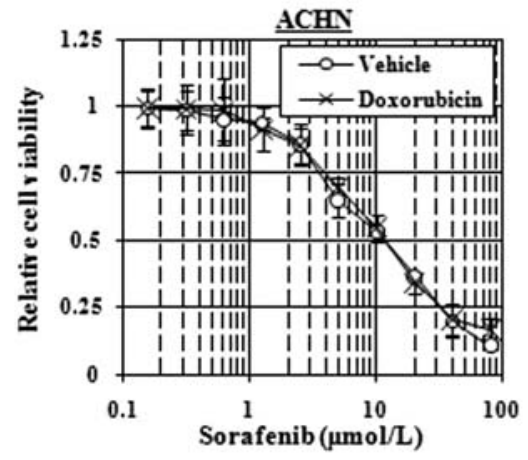

Figure 6. Doxorubicin sensitizes both Caki-1 and 786-O cells to sorafenib (A-C) Caki-1 (A), 786-O (B) and ACHN (C) cells were seeded into 96-well plates and treated with $1 \mathrm{nM}$ of doxorubicin. The following day, various concentrations of sorafenib were applied. After $48 \mathrm{~h}$, cell survival was analyzed by cytotoxicity assay. Cell survival in the absence of doxorubicin corresponds to 1 . All values are representative of at least three independent experiments. Boxes, mean; bars $\pm \mathrm{SD}$.

probably due to disorder of a mechanism of UPR (43). Elevation of serum lipase, pancreatic disorder and druginduced pancreatitis could occasionally occur during sorafenib administration, suggesting that multikinase inhibitor; sorafenib inhibits PERK activation (44). As expected, results clearly showed that phosphorylation level of eIF $2 \alpha$ was reduced by sorafenib treatment in Caki-1 and 786-O cells (Fig. 1A). There are four eIF $2 \alpha$ kinases, that is, HRI, PRK, PERK and GCN2. In RCC cells, the latter three eIF2 $\alpha$ kinases are expressed. Sorafenib was able to suppress PERK phosphorylation level. Therefore, sorafenib is suggested to reduce phosphorylation of eIF $2 \alpha$ through an inhibition of PERK kinase activity in Caki-1 and 786-O cells. However, eIF $2 \alpha$ phosphorylation level was inversely increased by sorafenib treatment in ACHN cells. Although exact mechanism could not be revealed, PERK mutation may affect inhibitory effect by sorafenib similar to FLT3 (45). This paradoxical response was shown in another study reporting that phosphorylated form of MEK, sorafenib target kinase, was increased in response to sorafenib in cells containing high level of B-Raf and low Ras activity (46). In addition, this opposite response of p-eIF $2 \alpha$ to sorafenib treatment may determine cell fate after sorafenib administration because increases of p-PERK and p-eIF $2 \alpha$ can rescue cell death induced by ER stress $(27,30)$. Furthermore, a newly revealed finding in this study that sorafenib could inhibit a kinase other than the previously known targets suggests that multikinase inhibitor may indeed inhibit kinases more than thought and that comprehensive assay to global kinases should be performed, which is supported by the previous finding that sorafenib interacted with relatively broad spectrum of kinases (47). Discrepancy in degree of cell cycle arrest at G2 phase and cell death between sorafenib treatment and PERK knockdown may suggest that sorafenib prevents activation of other kinases.

Imatinib is a multikinase inhibitor suppressing BCR-ABL, c-kit and PDGFR. The mechanism of imatinib resistance in chronic myeloid leukemia appears to result from the emergence of mutations in the kinase domain of BCR-ABL (48). In addition, a product of $M D R$ gene, P-glycoprotein and human organic cation transporter family member 1 (hOCT1) are suggested to be a molecular predictor of imatinib treatment in chronic myeloid leukemia $(49,50)$. Furthermore, imatinib resistance in gastrointestinal stromal tumors by second mutations of imatinib target, c-kit was reported $(51,52)$. Although sorafenib is used widely in many countries, predictive molecular markers of therapeutic efficiency have not been elucidated. Naturally, sorafenib exhibits therapeutic effects and adverse events differentially on individuals. It is very important for ideal treatment of mRCC to distinguish patients who are likely to benefit from sorafenib administration. In this study, phosphorylation ratio of eIF $2 \alpha$ and its associated molecule, Nrf2 was shown to be possibly useful in predicting efficiency of sorafenib administration, although this finding should to be confirmed in in vivo model and in clinical setting.

It is important to improve the outcome of $\mathrm{mRCC}$ patients. Cytokine therapy using IL-2 or IFN- $\alpha$ has been employed for the treatment of mRCC, however, outcomes have been unsatisfactory $(7,9,10)$. Recently, new small molecule agents were started to be administered for $\mathrm{mRCC}$ patients, and one of them is sorafenib. Although sorafenib improved progression-free survival and overall survival, its benefit is limited $(18,19)$. Therefore, more beneficial therapeutics is needed for RCC patients. Recently, sorafenib in combination with doxorubicin has been reported to double the median overall survival from 6.5 months in the doxorubicin-mono therapy group to 13.7 months in the combination group in a randomized, double-blind, placebo-controlled phase II study of patients with hepatocellular carcinoma, indicating the possibility of better sorafenib effect in combination with doxorubicin (53). However, sorafenib in combination with conventional chemotherapeutic agents, paclitaxel plus carboplatin for melanoma patients failed to show improvement in overall survival (54). In our study, sorafenib in vitro sensitized RCC cells possessing high eIF $2 \alpha$ phosphorylation 
status and nuclear Nrf2 expression level to oxidative stress exerted by hydrogen peroxide and doxorubicin, indicating that combination therapy of anticancer agents exerting oxidative stress and sorafenib may be a beneficial in the RCC dependent on PERK pathway. This finding is supported by the previous report that doxorubicin with sorafenib have an over-additive growth-inhibitory effect (55). In addition, some anticancer agents combined with anti-angiogenic drugs could improve therapeutic index through their anti-angiogenic effects (56). As it was shown that in mouse model, doxorubicin combined with anti-VEGFR2 antibody could exert an excellent therapeutic effect (57), sorafenib plus doxorubicin might be a novel method in terms of antiangiogenic therapeutics. Metronomic therapy has also been focused on in anti-angiogenic therapy. Sorafenib plus doxorubicin might be an ideal combination because nontoxic dose of doxorubicin could enhance cytotoxic effect of sorafenib, which prevent neovascularization and revascularization after maximum-tolerated dose chemotherapy (58). However, further investigation of the effect of the sorafenib and doxorubicin combination using in vivo models and in clinical trials are necessary to confirm the promising in vitro results reported here.

In conclusion, the multikinase inhibitor sorafenib was found to inhibit the PERK pathway regulating protein translation in the cells possessing high p-eIF $2 \alpha$ level and high nuclear Nrf2 expression. Furthermore, its pharmacological effects on the phosphorylation ratio of eIF $2 \alpha$ and its associated molecule, Nrf2 might be useful to predict efficiency of sorafenib administration. Silencing of PERK sensitized RCC cells to hydrogen peroxide and doxorubicin, probably due to oxidative stress. In addition, PERK inhibitor, sorafenib also sensitized to hydrogen peroxide and doxorubicin. Conversely, doxorubicin could sensitize to sorafenib. These findings indicate that doxorubicin might be a useful agent for treatment of $\mathrm{mRCC}$ patients in combination with sorafenib.

\section{Acknowledgements}

This work was supported in part by Health Sciences Research Grants for Clinical Research for Evidenced Based Medicine and Grants-in-Aid for Cancer Research (016), from the Ministry of Health, Labor and Welfare, Japan. We would like to thank Dr Kazuo Gohji (Kobe University, Kobe, Japan) for the gift of KG2 cells, Dr Dongchon Kang (Kyushu University, Fukuoka, Japan) for helping with flow cytometry, and Noriko Hakoda and Seiko Kamori for their technical assistance.

\section{References}

1. Turner KJ, Moore JW, Jones A, et al: Expression of hypoxiainducible factors in human renal cancer: relationship to angiogenesis and to the von Hippel-Lindau gene mutation. Cancer Res 62: 2957-2961, 2002

2. Gunaratnam L, Morley M, Franovic A, et al: Hypoxia inducible factor activates the transforming growth factor-alpha/epidermal growth factor receptor growth stimulatory pathway in VHL(-/-) renal cell carcinoma cells. J Biol Chem 278: 44966-44974, 2003.

3. Rafty LA and Khachigian LM: von Hippel-Lindau tumor suppressor protein represses platelet-derived growth factor Bchain gene expression via the $\mathrm{Sp} 1$ binding element in the proximal PDGF-B promoter. J Cell Biochem 85: 490-495, 2002.
4. Gunningham SP, Currie MJ, Han C, et al: Vascular endothelial growth factor-B and vascular endothelial growth factor- $\mathrm{C}$ expression in renal cell carcinomas: regulation by the von HippelLindau gene and hypoxia. Cancer Res 61: 3206-3211, 2001.

5. Kaelin WG Jr: The von Hippel-Lindau tumor suppressor gene and kidney cancer. Clin Cancer Res 10: S6290-S6295, 2004.

6. Stadler WM: Targeted agents for the treatment of advanced renal cell carcinoma. Cancer 104: 2323-2333, 2005.

7. Medical Research Council Renal Cancer Collaborators: Interferon-alfa and survival in metastatic renal carcinoma: early results of a randomised controlled trial. Lancet 353: 14-17, 1999.

8. Yagoda A, Abi-Rached B and Petrylak D: Chemotherapy for advanced renal-cell carcinoma: 1983-1993. Semin Oncol 22: 42-60, 1995.

9. Fyfe G, Fisher RI, Rosenberg SA, Sznol M, Parkinson DR and Louie AC: Results of treatment of 255 patients with metastatic renal cell carcinoma who received high-dose recombinant interleukin-2 therapy. J Clin Oncol 13: 688-696, 1995.

10. McDermott DF, Regan MM, Clark JI, et al: Randomized phase III trial of high-dose interleukin-2 versus subcutaneous interleukin- 2 and interferon in patients with metastatic renal cell carcinoma. J Clin Oncol 23: 133-141, 2005.

11. Dutcher JP, Logan T, Gordon M, et al: Phase II trial of interleukin 2, interferon alpha, and 5-fluorouracil in metastatic renal cell cancer: a cytokine working group study. Clin Cancer Res 6: 3442-3450, 2000.

12. Motzer RJ, Murphy BA, Bacik J, et al: Phase III trial of interferon alfa-2a with or without 13-cis-retinoic acid for patients with advanced renal cell carcinoma. J Clin Oncol 18: 2972-2980, 2000 .

13. Hernberg M, Virkkunen $\mathrm{P}$, Bono $\mathrm{P}$, Ahtinen $\mathrm{H}$, Mäenpää $\mathrm{H}$ and Joensuu $\mathrm{H}$ : Interferon alfa- $2 \mathrm{~b}$ three times daily and thalidomide in the treatment of metastatic renal cell carcinoma. J Clin Oncol 21: 3770-3776, 2003.

14. Wilhelm S and Chien DS: BAY 43-9006: preclinical data. Curr Pharm Des 8: 2255-2257, 2002.

15. Lyons JF, Wilhelm S, Hibner B and Bollag G: Discovery of a novel Raf kinase inhibitor. Endocr Relat Cancer 8: 219-225, 2001.

16. Wilhelm SM, Carter C, Tang L, et al: BAY 43-9006 exhibits broad spectrum oral antitumor activity and targets the RAF/ MEK/ERK pathway and receptor tyrosine kinases involved in tumor progression and angiogenesis. Cancer Res 64: 7099-7109, 2004.

17. Eto $\mathrm{M}$ and Naito S: Molecular targeting therapy for renal cell carcinoma. Int J Clin Oncol 11: 209-213, 2006

18. Abou-Alfa GK, Schwartz L, Ricci S, et al: Phase II study of sorafenib in patients with advanced hepatocellular carcinoma. J Clin Oncol 24: 4293-4300, 2006.

19. Escudier B, Eisen T, Stadler WM, et al: Sorafenib in advanced clear-cell renal-cell carcinoma. N Engl J Med 356: 125-134, 2007.

20. Akaza H, Tsukamoto T, Murai M, Nakajima K and Naito S: Phase II study to investigate the efficacy, safety, and pharmacokinetics of sorafenib in Japanese patients with advanced renal cell carcinoma. Jpn J Clin Oncol 37: 755-762, 2007.

21. Dever TE: Gene-specific regulation by general translation factors. Cell 108: 545-556, 2002.

22. Holcik M and Sonenberg N: Translational control in stress and apoptosis. Nat Rev Mol Cell Biol 6: 318-327, 2005.

23. Wek RC, Jiang HY and Anthony TG: Coping with stress: eIF2 kinases and translational control. Biochem Soc Trans 34: 7-11, 2006.

24. Ron D and Walter P: Signal integration in the endoplasmic reticulum unfolded protein response. Nat Rev Mol Cell Biol 8: 519-529, 2007.

25. Marciniak SJ and Ron D: Endoplasmic reticulum stress signaling in disease. Physiol Rev 86: 1133-1149, 2006.

26. Schröder M and Kaufman RJ: The mammalian unfolded protein response. Annu Rev Biochem 74: 739-789, 2005.

27. Harding HP, Zhang Y, Zeng H, et al: An integrated stress response regulates amino acid metabolism and resistance to oxidative stress. Mol Cell 11: 619-633, 2003.

28. Vattem KM and Wek RC: Reinitiation involving upstream ORFs regulates ATF4 mRNA translation in mammalian cells. Proc Natl Acad Sci USA 101: 11269-11274, 2004.

29. Lu PD, Harding HP and Ron D: Translation reinitiation at alternative open reading frames regulates gene expression in an integrated stress response. J Cell Biol 167: 27-33, 2004. 
30. Cullinan SB, Zhang D, Hannink M, Arvisais E, Kaufman RJ and Diehl JA: Nrf2 is a direct PERK substrate and effector of PERK-dependent cell survival. Mol Cell Biol 23: 7198-7209, 2003.

31. Wek RC and Cavener DR: Translational control and the unfolded protein response. Antioxid Redox Signal 9: 23572371,2007

32. Naito S, Kotoh S, Goto K, et al: Establishment of two human renal cell carcinoma cell lines with different chemosensitivity. Hum Cell 9: 101-108, 1996.

33. Naito S, Kanamori T, Hisano S, Tanaka K, Momose S and Kamata N: Human renal cell carcinoma: establishment and characterization of two new cell lines. J Urol 128: 1117-1121, 1982.

34. Naito S, von Eschenbach AC and Fidler IJ: Different growth pattern and biologic behavior of human renal cell carcinoma implanted into different organs of nude mice. J Natl Cancer Inst 78: 377-385, 1987

35. Gohji K, Fidler IJ, Tsan R, et al: Human recombinant interferonsbeta and -gamma decrease gelatinase production and invasion by human KG-2 renal-carcinoma cells. Int J Cancer 58: 380-384, 1994.

36. Shiota $\mathrm{M}$, Izumi $\mathrm{H}$, Onitsuka $\mathrm{T}$, et al: Twist promotes tumor cell growth through YB-1 expression. Cancer Res 68: 98-105, 2008.

37. Shiota M, Izumi $\mathrm{H}$, Onitsuka $\mathrm{T}$, et al: Twist and p53 reciprocally regulate target genes via direct interaction. Oncogene 27 : 5543-5553, 2008.

38. Shiota M, Izumi H, Miyamoto N, et al: Ets regulates peroxiredoxin 1 and 5 expressions through their interaction with the high mobility group protein B1. Cancer Sci 99: 1950-1959, 2008.

39. Shiota M, Izumi H, Tanimoto A, et al: Programmed cell death protein 4 down-regulates Y-box binding protein-1 expression via a direct interaction with Twist1 to suppress cancer cell growth. Cancer Res 69: 3148-3156, 2009.

40. Miyamoto N, Izumi H, Noguchi T, et al: Tip60 is regulated by circadian transcription factor clock and is involved in cisplatin resistance. J Biol Chem 283: 18218-18226, 2008

41. Benchekroun MN, Catroux P, Montaudon D and Robert J: Development of mechanisms of protection against oxidative stress in doxorubicin-resistant rat tumoral cells in culture. Free Radic Res Commun 11: 137-144, 1990.

42. Rahmani M, Davis EM, Crabtree TR, et al: The kinase inhibitor sorafenib induces cell death through a process involving induction of endoplasmic reticulum stress. Mol Cell Biol 27: 5499-5513, 2007.

43. Shi Y, An J, Liang J, et al: Characterization of a mutant pancreatic eIF-2alpha kinase, PEK, and co-localization with somatostatin in islet delta cells. J Biol Chem 274: 5723-5730, 1999.

44. Kane RC, Farrell AT, Saber H, et al: Sorafenib for the treatment of advanced renal cell carcinoma. Clin Cancer Res 12: 7271-7278, 2006.

45. Zhang W, Konopleva M, Shi Y, et al: Mutant FLT3: a direct target of sorafenib in acute myelogeneous leukemia. J Natl Cancer Inst 100: 184-198, 2008.
46. Ambrosini G, Cheema HS, Seelman S, et al: Sorafenib inhibits growth and mitogen-activated protein kinase signaling in malignant peripheral nerve sheath cells. Mol Cancer Ther 7: 890-896, 2008

47. Fabian MA, Biggs III WH, Treiber DK, et al: A small molecularkinase interaction map for clinical kinase inhibitors. Nat Biotechnol 23: 329-336, 2005.

48. Willis SG, Lange T, Demehri S, et al: High-sensitivity detection of BCR-ABL kinase domain mutations in imatinib-naïve patients: correlation with clonal cytogenetic evolution but not response to therapy. Blood 106: 2128-2137, 2005.

49. Thomas J, Wang I, Clark RE and Pirmohamed M: Active transport of imatinib into and out of cells: implications for drug resistance. Blood 104: 3739-3745, 2004.

50. Wang L, Giannoudis A, Lane S, Williamson P, Pirmohamed M and Clark RE: Expression of the uptake drug transporter hOCT1 is an important clinical determinant of the response to imatinib in chronic myeloid leukemia. Clin Pharmacol Ther 83: 258-264, 2008.

51. Chen LL, Trent JC, Wu EF, et al: A missense mutation in Kit kinase domain 1 correlates with imatinib resistance in gastrointestinal stromal tumors. Cancer Res 64: 5913-5919, 2004.

52. Antonescu CR, Besmer P, Guo T, et al: Acquired resistance to imatinib in gastrointestinal stromal tumor occurs through secondary gene mutation. Clin Cancer Res 11: 4182-4190, 2005.

53. Richly H, Schultheis B, Adamietz IA, et al: Combination of sorafenib and doxorubicin in patients with advanced hepatocellular carcinoma: results from a phase I extension trial. Eur J Cancer 45: 579-587, 2009.

54. Hauschild A, Agarwala SS, Trefzer U, et al: Results of a phase III, randomized, placebo-controlled study of sorafenib in combination with carboplatin and paclitaxel as second-line treatment in patients with unresectable stage III or stage IV melanoma. J Clin Oncol 27: 2823-2830, 2009.

55. Huether A, Höpfner M, Baradari V, Schuppan D and Scherübl H: Sorafenib alone or as combination therapy for growth control of cholangiocarcinoma. Biochem Pharmacol 73: 1308-1317, 2007.

56. Kerbel RS and Kamen BA: The anti-angiogenic basis of metronomic chemotherapy. Nat Rev Cancer 4: 423-436, 2004.

57. Zhang L, Yu D, Hicklin DJ, Hannay JA, Ellis LM and Pollock RE: Combined anti-fetal liver kinase 1 monoclonal antibody and continuous low-dose doxorubicin inhibits angiogenesis and growth of human soft tissue sarcoma xenografts by induction of endothelial cell apoptosis. Cancer Res 62: 2034-2042, 2002.

58. Pietras K and Hanahan D: A multitargeted, metronomic, and maximum-tolerated dose 'chemo-switch' regimen is antiangiogenic, producing objective responses and survival benefit in a mouse model of cancer. J Clin Oncol 23: 939-952, 2005. 